\title{
Integrating Ecology and Economics for Restoration: Using Ecological Indicators in Valuation of Ecosystem Services
}

Eric T. Schultz

University of Connecticut -Storrs, eric.schultz@uconn.edu

Robert Johnston

Clark University, rjohnston@clarku.edu

Kathleen Segerson

University of Connecticut, kathleen.segerson@uconn.edu

Elena Y. Besedin

Abt Associates, elena_besedin@abtassoc.com

Follow this and additional works at: https://opencommons.uconn.edu/eeb_articles

Part of the Agricultural and Resource Economics Commons, and the Terrestrial and Aquatic Ecology Commons

\section{Recommended Citation}

Schultz, Eric T.; Johnston, Robert; Segerson, Kathleen; and Besedin, Elena Y., "Integrating Ecology and Economics for Restoration: Using Ecological Indicators in Valuation of Ecosystem Services" (2012). EEB Articles. 28.

https://opencommons.uconn.edu/eeb_articles/28 
Integrating Ecology and Economics for Restoration:

\title{
Using Ecological Indicators in Valuation of Ecosystem Services
}

\author{
Eric T. Schultz ${ }^{1}$ \\ University of Connecticut \\ Robert J. Johnston \\ Clark University \\ Kathleen Segerson \\ University of Connecticut \\ Elena Y. Besedin \\ Abt Associates
}

Running title: Ecological Indicators in Valuation of Ecosystem Services

Submission Category: Review article

Keywords: aquatic ecology, fish passage, nonmarket, stated preference, survey

${ }^{1}$ Corresponding Author:

Department of Ecology and Evolutionary Biology

University of Connecticut

Storrs CT 06269-3043

Ph: (860) 486-4692 (voice)

Eric.schultz@uconn.edu 


\begin{abstract}
Because it can uniquely furnish insights into nonuse values for ecosystem services, survey-based Stated Preference (SP) valuation is widely used to estimate the benefits of ecological restoration. SP surveys ask respondents to select among restoration options yielding different ecological outcomes. This review examines the representation of ecological outcomes in SP studies seeking to quantify values for restoration of aquatic ecosystems. To promote the validity of ecological indicators used in SP valuation, we identified four standards: indicators should be measurable, interpretable, applicable, and comprehensive. We reviewed recent SP studies estimating the value of aquatic ecosystem services to assess whether ecological indicators in current use had these desirable properties. More than half of the 54 indicators reviewed were measurable, meaning referable to potentially precise quantification. About one third were interpretable, i.e., presented in a way that facilitates understanding the effects of restoration. About three quarters of the indicators were applicable; SP valuation practitioners typically consult with natural scientists to ensure that indicators represent the effect of stressors on ecological systems, and with focus groups to ensure that indicators have a connection with ecosystem services that contribute to public well-being. While most of the SP studies employed diverse and potentially comprehensive indicators that could capture direct and indirect effects of restoration, and six of twenty studies used indicators that met all standards, shortcomings in the indicators were common. These problems can be rectified with attention to how natural scientists measure change, and to relationships between restoration outcomes and characteristics of fully-restored reference ecosystems.
\end{abstract}

Keywords: aquatic ecology, choice experiment, nonmarket, stated preference, survey 


\section{Introduction}

Improving the provision of ecosystem services to enhance human welfare is widely recognized as a goal of natural resource policy and management, including ecological restoration (Turner \& Daily 2008; US EPA Science Advisory Board 2009). Although many ecologists may be reluctant to see economic valuation of ecosystems play a major role in policy making, quantifying the value of ecosystem services can, at a minimum, help ensure that restoration decisions consider the relevance of ecosystems to human welfare. Nonmarket valuation tools (Freeman 2003) are employed to quantify welfare enhancements when ecosystem service benefits from restoration are provided outside of traditional human markets (as they often are). Nonmarket valuation of ecosystem services entails explicit integration of ecology and economics. Ecological data and models are needed to characterize the condition and/or change in ecological systems that provide human benefits. Economic methods are then employed to define and value resulting services within frameworks that correspond to the norms of benefit cost analysis. The validity of the resulting value estimates depends on employing sound ecological and economic methods and on appropriately integrating these components.

Stated preference (SP) methods are a type of nonmarket valuation frequently used to quantify values associated with ecosystem change (Freeman 2003); these involve analysis of responses to surveys representing scenarios of ecosystem change through ecological indicators. When applied appropriately, these methods allow quantification of total nonmarket benefits (and their components) and tradeoffs provided by ecological restoration. However, when surveys incorporate ambiguous representations of ecosystem change, value estimates will be imprecise or biased, especially when survey respondents have little experience with the ecosystem goods or services in question. 
This review examines recent indicators used in SP valuation, focusing on analyses associated with aquatic ecosystem restoration. For context, we first provide background on SP methods and on how ecological changes are represented via indicators. We then suggest a set of standards representing best practices for indicators used in SP studies. We also assess the state of the field by examining indicators used in recent SP studies of aquatic ecosystems. The authors' collaboration, reflected in this review, came about to promote the integration of ecological and economic information for the quantification of ecosystem service values. Here we attempt to identify the properties of indicators that best bring this integration about, and to gauge the extent of the integration in the current literature.

\section{The Economic Component: Values and Valuation Methods for Ecosystem Services}

Despite their diversity, economic methods for valuing ecosystem services have common characteristics (Freeman 2003). In all methods, values are assessed with respect to well-defined marginal ecological changes, and are quantified using metrics that can be linked to improvements in human welfare (Bockstael et al. 2000; US EPA Science Advisory Board 2009). Within economics, willingness to pay (WTP) is the most common measure of value, reflecting the maximum amount of money or some other good or service that an individual would be willing to give up in exchange for more of something else (such as ecosystem restoration). Nonmarket valuation provides a means of measuring WTP for goods and services that are not traded in commercial markets (Freeman 2003).

Nonmarket valuation uses revealed preference (RP) and SP methods. RP methods directly address use values, those related to observable uses of resources or ecosystem services. SP methods are applicable to a wider range of ecosystem services and measure total values, including both use and nonuse values, those unrelated to observed uses, and including existence 
and bequest values (Freeman 2003; Bateman et al. 2011).

A common SP method is the choice experiment (CE: Adamowicz et al. 1998), in which surveys ask respondents to choose among a set of hypothetical but realistic options, similar to a public referendum presenting several policies. Each option is described by multiple attributes and information on household cost. For example, a marsh restoration program might be defined in terms of effects on land use, hydrology, the abundance of various wildlife species, and required taxes. Survey data consisting of choices over many sets of hypothetical, multi-attribute options enables WTP estimation.

SP methods are widely used, albeit with considerable controversy. Their widespread use is partially attributable to their capacity to furnish unique insights into values for ecosystem services. We do not offer a comprehensive review of the method's advantages and limitations, but focus on one challenging feature of survey design that has a critical effect on the validity of SP-derived value estimates. SP surveys must provide accurate and sufficient information, because respondents can make well-informed choices only when they can understand the influence of ecological changes on their welfare (Bateman et al. 2011). SP surveys must also be succinct and evocative, because of constraints on the quantity and complexity of information that can be effectively communicated (Bateman et al. 2002; Christie et al. 2006).

\section{The Ecological Component: Characterizing Change with Indicators}

Attention to how natural systems are represented is an important part of SP valuation of ecosystem services. Appropriate representations typically require the grounding of each valuation effort in a conceptual model that includes: 1) stressors, the typically anthropogenic influences that can be affected by management; 2) linkages among system components; and, 3) well-defined and welfare-relevant ecological endpoints, defined as "ecological attributes or 
elements. . .that serve as inputs to the production of ecosystem services” (US EPA Science Advisory Board 2009). The relationship of ecological endpoints to goods and services valued by humans varies; some endpoints may themselves be directly valued by humans, while others may serve only as inputs to valued goods and services (Fisher et al. 2008; Bateman et al. 2011). Careful definition and communication of welfare-relevant endpoints is crucial for valid ecosystem service valuation (Christie et al. 2006; Boyd \& Banzhaf 2007).

Ecological indicators are measurable ecosystem features that serve as proxies for valued endpoints. Biodiversity, for example, a commonly-invoked endpoint that cannot be directly measured due to its multidimensional nature, is often represented by indicators such as species number (Christie et al. 2006). Multiple functions have been imputed to ecological indicators. Beyond their 'primary role' of reflecting the impact of specific stressors of interest (Niemi \& McDonald 2007), indicators also assist in quantifying the degree of current ecological impairment, assessing future effects, and diagnosing stressors (Naweedi 2005). Changes in ecological endpoints can also be summarized using multimetric indices, including widely-used Indices of Biotic Integrity (IBIs), designed to represent "the ability to support a community of organisms having a species composition, diversity and functional organization comparable to that of natural habitat of the region” (Jordan \& Smith 2005). IBIs are tailored to a geographic region and (typically aquatic) ecological system, and have been constructed for selected North American estuaries (Deegan et al. 1997) and for streams of eastern (Morgan \& Cushman 2005) and western (Mebane et al. 2003) North America. A terrestrial multimetric index is mean species abundance (MSA) of species inhabiting an ecosystem, relative to their abundance in a pristine equivalent (Alkemade et al. 2009).

The development of ecological indicators and indices has been accompanied by close 
scrutiny in the ecological literature of their efficacy. Criteria for ecological indicators that are useful in monitoring (e.g., Jackson et al. 2000; Naweedi 2005) include: 1) relevance with respect to endpoints and stressors; 2) feasibility with respect to cost-effective routine data collection; 3) accuracy with respect to sources of uncertainty; and, 4) interpretability with respect to discerning changes making management decisions. Because valid SP valuation requires that respondents accurately understand changes to ecological endpoints, appropriate use of ecological indicators is required to ensure meaningful value estimates. However, the close scrutiny given to indicators within the ecological literature has not been matched in the economics literature, leading to a disparity between indicators considered valid and useful in ecological science and those applied in economic valuation (Johnston et al. In press).

\section{Standards for Ecological Indicators within Stated Preference Valuation}

This section outlines a set of four simple standards for ecological indicators and indices used in SP valuation. In the course of designing our own SP analyses (Johnston et al. In press), we developed these standards by modifying recommendations for indicators used in ecological monitoring programs. The standards do not represent an exhaustive list but serve as minimal requirements enabling SP valuation to (1) provide information necessary and sufficient to elicit well-informed survey responses from non-experts, and (2) provide an accurate representation of ecosystem change resulting from restoration. That is, they are presented as necessary but not sufficient conditions.

Standard \#1: measurability. Indicators used within survey scenarios should have a clearly stated relationship to ecological data or model results; they should consist of measures that are, at a minimum, empirically quantifiable. If ordinal categories (e.g., high, low) are used, the empirical basis for these categories should be specified. Multimetric indices, where used, should 
be composed of a set of measurable indicators such as species number, abundance, and disease prevalence. This standard helps allay a common concern that SP surveys present ecological information in ways that cannot be traced back to quantifiable measures, and are thus inaccurate or lack meaning.

Standard \#2: interpretability. The different possible values for indicators should be understood similarly by respondents and scientists. Indicator measurability is a necessary but not sufficient condition for interpretability. Interpretability of measurable indicators is enhanced by scaling and presenting indicators such that respondents can identify baselines (i.e., status quo), reference conditions (i.e., the best possible level in an undisturbed system), and changes in both relative and cardinal units where applicable. The ecological context represented by reference conditions is important because it enables respondents to better comprehend policy scope (Heberlein et al. 2005); this is particularly important for ecosystem services, with which respondents often have limited experience and understanding (Bateman et al. 2011).

Standard \#3: applicability. Indicators in SP surveys should be germane to the restoration project. Developing such indicators requires a conceptual model of the natural system, so that indicators represent well-determined relationships between stressors and ecological endpoints. Furthermore, these endpoints must be linked to specific effects (i.e., changes in ecosystem services) over which respondents have preferences, as revealed by qualitative research methods such as focus groups and cognitive interviews (Powe 2007). This specificity helps prevent situations in which indicators are only indirectly related to respondent values, in which case respondents might make speculative inferences regarding omitted but relevant attributes (Carson 1998). For example, respondents might care about the abundance of migratory fish largely because of a perceived effect on a commercial fishery and local employment, even if there is 
little potential for such an effect. Sacrificing ecological applicability reduces the usefulness of SP data to inform decisions on restoration policy.

Standard \#4: comprehensiveness. As noted above, incomplete description of relevant effects can encourage speculation; respondents might fail to understand or appreciate fully the ecological importance of certain species or processes, and hence estimated economic values will not reflect the full impact of ecological changes (US EPA Science Advisory Board 2009). This is likely to be a concern for nonuse values or values stemming from regulating or supporting ecosystem services that are not readily perceptible and that influence respondents' welfare only indirectly (e.g., nutrient recycling provided by dung beetles: Nichols et al. 2008). Comprehensive specification of effects includes the direct effect(s) of proposed policies on targeted species or habitats (e.g., an increase in wetland area as a result of hydrological restoration) as well as indirect effects on ecosystem attributes or human uses that occur as consequences of the primary effects or as consequences of other indirect effects (e.g., changes in vegetation as a response to hydrological changes, colonization by animal species requiring wetland flora for habitat or food, etc.). The inclusion of ecological changes at multiple causal levels provides a basis for distinguishing between value for improvements in specific elements of the ecological system and that for overall ecosystem condition.

\section{Prior Stated Preference Studies Estimating Values for Aquatic Ecosystem Change}

To assess the extent to which ecological indicators in use had the minimum properties described by our standards, we reviewed recent SP studies that estimated the value of aquatic ecosystem services. We located roughly 700 studies in Web of Science (Thomson Reuters, New York NY), using search terms for economic methods (e.g. contingent valuation) combined with terms for aquatic systems (e.g. lake), in papers published in 2006 or later. We culled those that 
did not pertain to valuation of aquatic ecosystem services or changes, did not use indicators, or were not readily available, yielding a final set of 21 papers to review; Fenichel et al (2009) and Hoehn et al (2010) used the same survey and are treated here as one study. The papers reported 54 ecological indicators (Table 1; details in supplementary document). Although this is a small subset of the subject literature, the criteria we used were meant to furnish a representative view of ecological indicators used in current SP studies.

The indicators in recent SP studies can be grouped according to ecological endpoints they represent. The largest group consists of 14 indicators representing biodiversity (e.g., "number of fish species”, Do \& Bennett 2009). Indicators also commonly represented habitat quantity (n = 11, e.g., “wetland area”, Birol \& Cox 2007) or habitat quality (n = 9, e.g. "water clarity”, Kerr \& Sharp 2008). Seven indicators explicitly represented habitat functions (“erosion control”, Kataria 2009). Other indicators represented aesthetics (e.g., "litter and sewage”, Hanley et al. 2006b), human health (“risk of injury or illness”, McIntosh et al. 2010), productivity (e.g., "Number of salmon passing fish ladder”, Håkansson 2009), and recreation (e.g., "Suitability for playing in the river”, Nakatani et al. 2007). Several studies incorporated indices of ecological integrity similar to IBIs (Hanley et al. 2006a; Martin-Ortega et al. 2011).

More than half of the indicators $(n=30$; Table 1$)$ were measurable, in that they were referable to potentially precise quantification. Indicators of diversity often varied over precise values for species number (e.g., “2 protected bird species” Luisetti et al. 2011), and habitat quantity (e.g., “60\% of surface area is open water”, Birol et al. 2006). However, the choice set for some diversity indicators comprised ordinal categories whose meaning was not clear (e.g., “mostly desirable fish species with many walleye”, Christie \& Azevedo 2009). Habitat quality indicators, often presented in categories, were measurable when the categories were distinct 
classes (e.g., wooded wetland or marsh, Hoehn et al. 2010), or when the meaning of ordinal categories was spelled out (e.g., “an 'excellent' rating meant that the wetland habitat supported 'these species in better than average numbers...[so] a casual observer is very likely to see a variety of these species’” Hoehn et al. 2010). In contrast, some habitat quality indicators were not measurable (e.g., the choice set for “condition of waterholes' ranged from "poor” to "good”, Zander \& Straton 2010). Few multimetric indicators were measurable; they typically lacked units, and alternative outcomes were described in poorly-defined ordinal categories (see discussion in Christie et al. 2006). For instance, the choice set in Bateman et al. (2006) includes "plants and wildlife” in an ordinal scale ("plant growth, insects, birds and animal life limited”, “more plants would grow, waterfowl can use river”, up to “increase in plants and wildlife, possible for otters to survive”).

About one third of the indicators were interpretable (Table 1). Interpretability is a more stringent condition than measurability; indicators need to both have a measurable basis and also be expressed in a way that facilitates understanding the effects of restoration among non-expert respondents. Even studies that use measureable indices may fail to represent the potential scope of restoration. In a choice set example presented in Do and Bennett (2009), the number of fish species varied from 40 (baseline or status quo) to 50 or 70 under alternative restoration options. The interpretation of this change depends on how 70 species compares to the reference condition for this system. In contrast, the choice set for an indicator of species abundance in Milon \& Scrogin (2006) spells out the quantitative basis, baseline and reference conditions (e.g., "wetland dependent species such as wading birds and alligators” at “20\% of historic, predrainage population levels”). Recent studies reflect an appreciation for the value of making reference and baseline conditions clear; eight indicators that were not measurable nonetheless had choice sets 
that clearly represented both reference and baseline conditions, and another 19 represented baseline conditions without a reference condition.

Most of the indicators ( $n=40$; Table 1 ) were economically and ecologically applicable. Economic applicability entails having some demonstrated connection between the indicator and public well-being. Preparation of SP surveys commonly involves work with focus groups to ensure such a connection (Powe 2007), and we interpreted statements of focus group work in the description of a study’s method as evidence for economic applicability of the indicators. Ecological applicability entails having at least an implicit relationship among stressors, indicators, and ecological endpoints. To help ensure ecological applicability, it is crucial to consult with natural scientists (e.g. "Significant wetland management attributes pertaining to [the wetland] were identified in consultation with ecologists and hydrologists [and economists]. Three focus groups were then conducted .....to determine the final attributes and their levels that are important to the public, as well as the vocabulary and language to be used in the survey” Birol et al. 2006). Applicability may have been sacrificed in some studies in an effort to simplify survey representations of ecological consequences. For example, Hanley et al. (2006b p. 186) state, "none of these attributes are necessarily consistent with what an ecologist would choose in terms of either indicators of the ecological health of a waterbody, or underlying factors driving changes in ecological status.” We interpreted statements of collaboration with ecologists in the description of a study’s method as evidence for ecological applicability of its indicators.

Otherwise, we classified applicability as unclear. We did not use consultation with regulators, stakeholders or government officials as evidence of ecological applicability, given the unclear contribution of such consultations to the ecological content of indicators. Finally, indicators defined solely in terms of suitability of resources for human use, with no underlying ecological 
detail or justification, were also considered to have unclear ecological applicability.

Consistency with our fourth standard, that indicators should furnish a comprehensive depiction of ecological effects of restoration, is difficult to judge conclusively.

Comprehensiveness cannot be assessed one indicator at a time because it is a feature of entire SP scenarios. A minimum condition for comprehensiveness is including multiple indicators that together can represent direct and indirect responses to restoration. Three studies provided only one indicator (Tseng \& Chen 2008; Del Saz-Salazar et al. 2009; Håkansson 2009). The indicators presented in most of the studies $(n=12)$ potentially captured direct and indirect responses to restoration. Four studies omitted indicators that could capture the direct effect of restoration (e.g., changes in flooded area in response to dyke removal, Do \& Bennett 2009).

Has the use of ecological indicators in SP analyses improved over time? The collaboration of the authors was stimulated by the perception that ecological considerations had been poorly integrated into SP surveys. Nonetheless, some recent papers (especially Hoehn et al. 2010; Pattison et al. 2011) employed an especially comprehensive set of indicators that each fully met the recommended standards, suggesting that the field is increasingly incorporating best practices. Moreover, there are an increasing number of publications in the valuation literature that discuss the quantification and representation of various ecological effects (e.g., biodiversity, Christie et al. 2006), implying greater awareness of such concerns. Unfortunately, the limited 6year scope of the papers examined in this review does not permit a powerful test of temporal change.

In summary, our evaluation revealed wide variation in the presentation of ecological information within SP surveys. Six of twenty studies used indicators that met all of the standards. It is encouraging that nearly all of the SP studies took care to ensure ecological and 
economic applicability, and that the indicators used represented diverse and potentially comprehensive responses to restoration. However, we found rather widespread shortcomings with respect to the use of indicators that are explicitly quantifiable, and that are interpretable with respect to both unrestored and fully-restored conditions. Estimated values for restoration are likely to lack precision and accuracy as a result. It is important to note that our evaluation of ecological indicators used in an SP study is not intended as a comment on a study's overall quality, which can have many facets that are not considered in this limited review. Furthermore, our judgment of whether an indicator met the standards was based on entirely on what was presented in the published account, which may well have omitted information that would have changed our interpretation.

\section{Concluding Remarks}

Measurements of the conditions of ecological systems that are useful in designing and monitoring restoration projects are also useful in assessing the public costs and benefits of such projects. Indicators can play an important role in restoration and other forms of management; restoration projects, which are designed to ameliorate the effects of one or more ecosystem stressors, must at least implicitly conceive of how the success of the restoration would be judged. There is a robust literature providing guidance on ecological indicators for resource managers that stresses the importance of accurate and comprehensive quantification of ecosystem state. In this paper, we have argued that the properties of well-conceived indicators that make them useful in the design and monitoring of restoration are precisely the same as those needed in valuation of restoration's public benefits. Incorporating information about the value of ecological effects is critical for making sound decisions about public policies that impact the environment. SP surveys are now a commonly used method for estimating these values. The validity of resulting 
value estimates is conditional on an accurate representation of ecosystem change.

Our informal review of recent SP surveys focusing on aquatic restoration indicates mixed results. On the positive side, most of the studies we examined maintained a focus on ecological indicators that were relevant to restoration efforts. On the negative side, many of these indicators do not meet minimal standards for measurability or interpretability. This paper develops an initial set of standards designed to help ensure, in combination with other best practices, that SP-derived value estimates can be linked unambiguously to meaningful and measurable indicators.

As ecology and economics are undergoing a more thorough integration, the strengths and limitations of different approaches to valuation are of increasing interest. Some ecologists and economists regard the estimates provided by survey-based methods as less repeatable, less generalizable and in greater need of validation than those yielded by other approaches. It is well beyond the scope of this paper to compare and contrast the methods that are presently brought to bear on the valuation problem. In lieu of a broad critique, we emphasize that the SP method is distinct from other methods in several respects that recommend its use in restoration planning: these include its ability to quantify nonuse values and its direct approach to public attitudes. In a broader context than is represented in this review, valuation for project planning entails a dialogue among technical experts, chief stakeholders and other citizens, and the representation of ecological change as reflected in indicators plays a role in each part of this dialogue. The development and implementation of schemes that formally link multiple stages in project planning should prove fruitful (see Sijtsma et al. 2011 for one promising example). Our review also suggests that SP valuation, despite the controversies surrounding its use, has provided a platform for more widespread collaboration and dialogue among ecologists and economists. It is 
hoped that this paper will further promote such interactions.

We conclude by pointing to valuation challenges that must be addressed in order to more fully integrate ecology and economics. One challenge will be to assess whether well-crafted indicators reflect a rich sense of the value of natural systems. It will be interesting to map out where surveys succeed in providing sufficient background for respondents to make informed choices about indirect benefits; this will be especially challenging for supporting ecosystem services. Other issues that will require careful attention are the degree to which results of analyses can be generalized from one restoration project to another in a different time and place, and the degree to which results can be scaled up to values arising from national and global environmental policy (Sijtsma et al. 2011). 


\section{Implications for Practice}

- Insofar as ecological restoration seeks to enhance the delivery of ecosystem services, it entails valuation of these services. Stated preference valuation can quantify explicitly nonuse nonmarket values that are prominent in ecosystem service valuation.

- Integration of ecological and economic considerations in valuation efforts requires ongoing collaboration rather than time-limited consultation. Ecologists must play a role at all stages of formulation, design and execution of valuation projects.

- Valid estimates of value for ecosystem services require ecosystem indicators that are developed with attention to data and models, and are quantitative, interpretable, applicable and comprehensive. This is true of all approaches to valuation.

- Stated-preference approaches to valuation frequently use ecosystem indicators that are not likely to yield valid estimates of value. With care, it is possible to design surveys using indicators that comprehensively characterize ecosystem services in a fashion understandable to respondents. 
Schultz et al. Restoration Ecology MS p 18

\section{Acknowledgements}

We were assisted in research development and execution by Deepak Joglekar, Jessica Kukielka, Mahesh Ramachandran, Damiana Serafini, Ryan Stapler, John Tortorella, and Minjuan Zhao.

Robin Chazdon and anonymous reviewers provided constructive comments on manuscript drafts. This research was supported by the EPA Science to Achieve Results program, Grant \#RD 83242001 and 83242002 . Opinions and findings are those of the authors, and do not imply endorsement of the funding agency.

\section{References Cited}

Adamowicz, W., P. Boxall, M. Williams, and J. Louviere. 1998. Stated preference approaches for measuring passive use values: Choice experiments and contingent valuation. American Journal of Agricultural Economics 80:64-75.

Alkemade, R., M. Van Oorschot, L. Miles, C. Nellemann, M. Bakkenes, and B. Ten Brink. 2009. GLOBIO3: A Framework to Investigate Options for Reducing Global Terrestrial Biodiversity Loss. Ecosystems 12:374-390.

Bateman, I. J., R. T. Carson, B. Day, M. Hanemann, N. Hanley, T. Hett, M. Jones-Lee, G. Loomes, S. Mourato, E. Ozdemiroglu, D. W. Pearce, R. Sugden, and J. Swanson. 2002. Economic Valuation with Stated Preference Surveys: A Manual. Edward Elgar, Northampton MA

Bateman, I. J., M. A. Cole, S. Georgiou, and D. J. Hadley. 2006. Comparing contingent valuation and contingent ranking: A case study considering the benefits of urban river water quality improvements. Journal of Environmental Management 79:221-231.

Bateman, I. J., G. M. Mace, C. Fezzi, G. Atkinson, and K. Turner. 2011. Economic Analysis for Ecosystem Service Assessments. Environmental \& resource economics 48:177-218. 
Birol, E., and V. Cox. 2007. Using choice experiments to design wetland management programmes: The case of Severn Estuary wetland, UK. Journal of Environmental Planning and Management 50:363-380.

Birol, E., K. Karousakis, and P. Koundouri. 2006. Using a Choice Experiment to Account for Preference Heterogeneity in Wetland Attributes: The Case of Cheimaditida Wetland in Greece. Ecological Economics 60:145-156.

Bockstael, N. E., A. M. Freeman, R. J. Kopp, P. R. Portney, and V. K. Smith. 2000. On measuring economic values for nature. Environmental Science \& Technology 34:13841389.

Boyd, J., and S. Banzhaf. 2007. What are ecosystem services? The need for standardized environmental accounting units. Ecological Economics 63:616-626.

Carson, R. T. 1998. Valuation of tropical rainforests: philosophical and practical issues in the use of contingent valuation. Ecological Economics 24:15-29.

Christie, M., and C. D. Azevedo. 2009. Testing the Consistency Between Standard Contingent Valuation, Repeated Contingent Valuation and Choice Experiments. Journal of Agricultural Economics 60:154-170.

Christie, M., N. Hanley, J. Warren, K. Murphy, R. Wright, and T. Hyde. 2006. Valuing the diversity of biodiversity. Ecological Economics 58:304-317.

Deegan, L. A., J. T. Finn, S. G. Ayvazian, C. A. Ryder-Kieffer, and J. Buonaccorsi. 1997. Development and validation of an Estuarine Biotic Integrity Index. Estuaries 20:601-617. 
Del Saz-Salazar, S., F. Hernandez-Sancho, and R. Sala-Garrido. 2009. The social benefits of restoring water quality in the context of the Water Framework Directive: A comparison of willingness to pay and willingness to accept. Science of the Total Environment 407:4574-4583.

Do, T. N., and J. Bennett. 2009. Estimating wetland biodiversity values: a choice modelling application in Vietnam's Mekong River Delta. Environment and Development Economics 14:163-186.

Fenichel, E. P., F. Lupi, J. P. Hoehn, and M. D. Kaplowitz. 2009. Split-Sample Tests of "No Opinion" Responses in an Attribute-Based Choice Model. Land Economics 85:348-362.

Fisher, B., K. Turner, M. Zylstra, R. Brouwer, R. De Groot, S. Farber, P. Ferraro, R. Green, D. Hadley, J. Harlow, P. Jefferiss, C. Kirkby, P. Morling, S. Mowatt, R. Naidoo, J. Paavola, B. Strassburg, D. Yu, and A. Balmford. 2008. Ecosystem services and economic theory: Integration for policy-relevant research. Ecological Applications 18:2050-2067.

Freeman, A. M., III. 2003. The Measurement of Environmental and Resource Values: Theory and Methods. Resources for the Future, Washington DC

Håkansson, C. 2009. Costs and benefits of improving wild salmon passage in a regulated river. Journal of Environmental Planning and Management 52:345-363.

Hanley, N., S. Colombo, D. Tinch, A. Black, and A. Aftab. 2006a. Estimating the benefits of water quality improvements under the Water Framework Directive: are benefits transferable? Eur Rev Agric Econ 33:391-413.

Hanley, N., R. E. Wright, and B. Alvarez-Farizo. 2006b. Estimating the economic value of improvements in river ecology using choice experiments: an application to the water framework directive. Journal of Environmental Management 78:183-193. 
Heberlein, T. A., M. A. Wilson, R. C. Bishop, and N. C. Schaeffer. 2005. Rethinking the scope test as a criterion for validity in contingent valuation. Journal of Environmental Economics and Management 50:1-22.

Hoehn, J. P., F. Lupi, and M. D. Kaplowitz. 2010. Stated Choice Experiments with Complex Ecosystem Changes: The Effect of Information Formats on Estimated Variances and Choice Parameters. Journal of Agricultural and Resource Economics 35:568-590.

Jackson, L. E., J. C. Kurtz, and W. S. Fisher 2000. Evaluation Guidelines for Ecological Indicators. EPA/620/R-99/005. US EPA, Washington, DC.

Johnston, R. J., E. T. Schultz, K. Segerson, E. Y. Besedin, and M. Ramachandran. In press. Enhancing the content validity of stated preference valuation: the structure and function of ecological indicators. Land Economics $\mathbf{8 8}$.

Jordan, S. J., and L. M. Smith 2005. Indicators of ecosystem integrity for estuaries. Pages 467480 in S. A. Bortone, editor. Estuarine indicators. CRC Press, Boca Raton, FL.

Kataria, M. 2009. Willingness to pay for environmental improvements in hydropower regulated rivers. Energy Economics 31:69-76.

Kerr, G. N., and B. M. H. Sharp. 2008. Evaluating off-site environmental mitigation using choice modelling. Australian Journal of Agricultural and Resource Economics 52:381-399.

Luisetti, T., I. J. Bateman, and R. K. Turner. 2011. Testing the Fundamental Assumption of Choice Experiments: Are Values Absolute or Relative? Land Economics 87:284-296. Martin-Ortega, J., G. Giannoccaro, and J. Berbel. 2011. Environmental and Resource Costs Under Water Scarcity Conditions: An Estimation in the Context of the European Water Framework Directive. Water Resources Management 25:1615-1633. 
Mcintosh, C. R., J. F. Shogren, and D. C. Finnoff. 2010. Invasive species and delaying the inevitable: Valuation evidence from a national survey. Ecological Economics 69:632640.

Mebane, C. A., T. R. Maret, and R. M. Hughes. 2003. An Index of Biological Integrity (IBI) for Pacific Northwest Rivers. Transactions of the American Fisheries Society 132:239-261.

Milon, J. W., and D. Scrogin. 2006. Latent Preferences and Valuation of Wetland Ecosystem Restoration. Ecological Economics 56:162-175.

Morgan, R. P., and S. F. Cushman. 2005. Urbanization effects on stream fish assemblages in Maryland, USA. Journal of the North American Benthological Society 24:643-655.

Nakatani, J., T. Aramaki, and K. Hanaki. 2007. Applying choice experiments to valuing the different types of environmental issues in Japan. Journal of Environmental Management 84:362-376.

Naweedi, M. J. 2005. Environmental indicators as performance measures for improving estuarine environmental quality. Pages 451-465 in S. A. Bortone, editor. Estuarine indicators. CRC Press, Boca Raton, FL.

Nichols, E., S. Spector, J. Louzada, T. Larsen, S. Amezquita, and M. E. Favila. 2008. Ecological functions and ecosystem services provided by Scarabaeinae dung beetles. Biological Conservation 141:1461-1474.

Niemi, G. J., and M. E. Mcdonald. 2007. Application of ecological indicators. Annual Review of Ecology and Systematics 35:89-111.

Pattison, J., P. C. Boxall, and W. L. Adamowicz. 2011. The Economic Benefits of Wetland Retention and Restoration in Manitoba. Canadian Journal of Agricultural EconomicsRevue Canadienne D Agroeconomie 59:223-244. 
Powe, N. E. 2007. Redesigning Environmental Valuation: Mixing Methods within Stated Preference Techniques. Edward Elgar, Cheltenham, UK

Sijtsma, F. J., C. M. v. d. Heide, and A. v. Hinsberg 2011. Biodiversity and decision-support: integrating CBA and MCA. in A. Hull, E. Alexander, A. Khakee and J. Woltjer, editors. Evaluation for participation and sustainability in planning. Routledge, London.

Tseng, W. C., and C. C. Chen. 2008. Valuing the potential economic impact of climate change on the Taiwan trout. Ecological Economics 65:282-291.

Turner, R., and G. Daily. 2008. The Ecosystem Services Framework and Natural Capital Conservation. Environmental and Resource Economics 39:25.

US EPA Science Advisory Board. 2009. Valuing the Protection of Ecological Systems and Services. EPA-SAB-09-012.

Zander, K. K., and A. Straton. 2010. An economic assessment of the value of tropical river ecosystem services: Heterogeneous preferences among Aboriginal and non-Aboriginal Australians. Ecological Economics 69:2417-2426. 
Table 1. Summary of indicator analysis. For each of 21 studies (2 of which use the same SP dataset and are thus combined in a row), entries in the table include the number of ecological indicators, followed by the number of indicators that we regard as measurable and interpretable, and whether the indicators were applicable (Y: yes; U: unclear) and comprehensive (Y: yes; N: no) according to our criteria. Judgment of whether an indicator met the standards was based on entirely on what was presented in the published account, which may have omitted information that would have changed our interpretation.

\begin{tabular}{|c|c|c|c|c|c|}
\hline N(indicators) & $\mathrm{N}$ (measurable) & N(interpretable) & Applicable & Comprehensive & Reference \\
\hline 3 & 1 & 3 & $\mathrm{U}$ & $\mathrm{Y}$ & Bateman et al. 2006 \\
\hline 2 & 1 & 0 & $\mathrm{Y}$ & $\mathrm{Y}$ & Birol et al. 2006 \\
\hline 1 & 0 & 0 & $\mathrm{U}$ & $\mathrm{N}$ & Hanley et al. 2006a \\
\hline 3 & 0 & 0 & $\mathrm{U}$ & $\mathrm{Y}$ & Hanley et al. 2006b \\
\hline 2 & 2 & 2 & $\mathrm{Y}$ & $\mathrm{Y}$ & Milon \& Scrogin 2006 \\
\hline 3 & 3 & 1 & $\mathrm{U}$ & $\mathrm{Y}$ & Birol \& Cox 2007 \\
\hline 2 & 1 & 1 & $\mathrm{U}$ & $\mathrm{Y}$ & Nakatani et al. 2007 \\
\hline 5 & 2 & 5 & $\mathrm{Y}$ & $\mathrm{Y}$ & Kerr \& Sharp 2008 \\
\hline \multirow[t]{2}{*}{1} & 1 & 1 & $\mathrm{Y}$ & $\mathrm{N}$ & Tseng \& Chen 2008 \\
\hline & & & & & Christie \& Azevedo \\
\hline \multirow[t]{2}{*}{4} & 3 & 0 & $\mathrm{Y}$ & $\mathrm{N}$ & 2009 \\
\hline & & & & & Del Saz-Salazar et al. \\
\hline 1 & 0 & 0 & $\mathrm{U}$ & $\mathrm{N}$ & 2009 \\
\hline \multirow[t]{2}{*}{3} & 3 & 0 & $\mathrm{Y}$ & $\mathrm{N}$ & Do \& Bennett 2009 \\
\hline & & & & & Fenichel et al. 2009; \\
\hline 3 & 3 & 3 & $\mathrm{Y}$ & $\mathrm{Y}$ & Hoehn et al. 2010 \\
\hline 1 & 1 & 0 & $\mathrm{Y}$ & $\mathrm{N}$ & Håkansson 2009 \\
\hline 4 & 1 & 0 & $\mathrm{Y}$ & $\mathrm{Y}$ & Kataria 2009 \\
\hline
\end{tabular}


4

3

2

1

6
0

1

2

0

6
0

3

1

1

6
Y

Y

Y

$\mathrm{Y}$

Y
Y

Y

Y

Y
McIntosh et al. 2010

Zander \& Straton 2010

Luisetti et al. 2011

Martin-Ortega et al. 2011

Pattison et al. 2011 
Ecological indicators in recent stated preference valuation analyses of aquatic ecosystem services. Each indicator is represented on a separate row, except where noted. Some indicator descriptions are simplified for clarity of presentation. To more fully describe each indicator, the table provides: 1) one or more welfare-relevant ecological endpoints for each indicator (see text for distinction between endpoints and indicators); 2) lower and upper limits (as lower / upper) to the range of indicator values, omitting intermediate values if any for conciseness. Each indicator is scored according to whether it meets three guidelines: measurable if field workers could unambiguously score its value (yes/no), interpretable if both baseline and reference values were clear (yes/no), and applicable if the published account reported both consultation with ecologists and focus groups as a basis for indicator development (yes/unclear). To illustrate the comprehensiveness of indicators used in a particular study, the table also provides the environmental stressors that the restoration project reported in the study was designed to ameliorate, and whether the indicator reflected a direct or indirect effect of the restoration.

\begin{tabular}{|c|c|c|c|c|c|c|c|c|}
\hline $\begin{array}{l}\text { Bioindicator } \\
\text { description }\end{array}$ & $\begin{array}{l}\text { Ecological } \\
\text { endpoint(s) }\end{array}$ & $\begin{array}{l}\text { Range of } \\
\text { values }\end{array}$ & Measurable & Interpretable & Applicable & Stressor & $\begin{array}{l}\text { Direct / } \\
\text { indirect } \\
\text { effect }\end{array}$ & Reference \\
\hline & & $\begin{array}{l}\text { No fish / } \\
\text { game fish }\end{array}$ & & & & & & \\
\hline $\begin{array}{l}\text { Fish species } \\
\text { number }\end{array}$ & Biodiversity & $\begin{array}{l}\text { plus } \\
\text { salmonids }\end{array}$ & Yes & Yes & Unclear & $\begin{array}{l}\text { Adverse water } \\
\text { quality }\end{array}$ & Indirect & Bateman et al. 2006 \\
\hline
\end{tabular}


Schultz et al. Restoration Ecology MS Supplementary Document p 2

\begin{tabular}{|c|c|c|c|c|c|c|c|c|}
\hline Plant growth, & Biodiversity & & & & & & & \\
\hline insects, birds & and & Limited / & & & & Adverse water & & \\
\hline and wildlife & productivity & Increase & No & Yes & Unclear & quality & Indirect & Bateman et al. 2006 \\
\hline Boating and & & Unsuitable / & & & & Adverse water & & \\
\hline swimming & Recreation & suitable & No & Yes & Unclear & quality & Direct & Bateman et al. 2006 \\
\hline \multicolumn{9}{|l|}{ Species } \\
\hline \multicolumn{9}{|l|}{ number and } \\
\hline abundance, & & Decrease / & & & & & & \\
\hline habitat & & $10 \%$ & & Reference & & Adverse water & & \\
\hline diversity and & & increase & & value & & quality and & & \\
\hline \multirow[t]{2}{*}{ size } & Biodiversity & from current & No & omitted & Yes & quantity & Indirect & Birol et al. 2006 \\
\hline & & & & Reference & & Adverse water & & \\
\hline Open water & Habitat & & & value & & quality and & & \\
\hline surface area & quantity & $<20 \%$ / $60 \%$ & Yes & omitted & Yes & quantity & Direct & Birol et al. 2006 \\
\hline
\end{tabular}




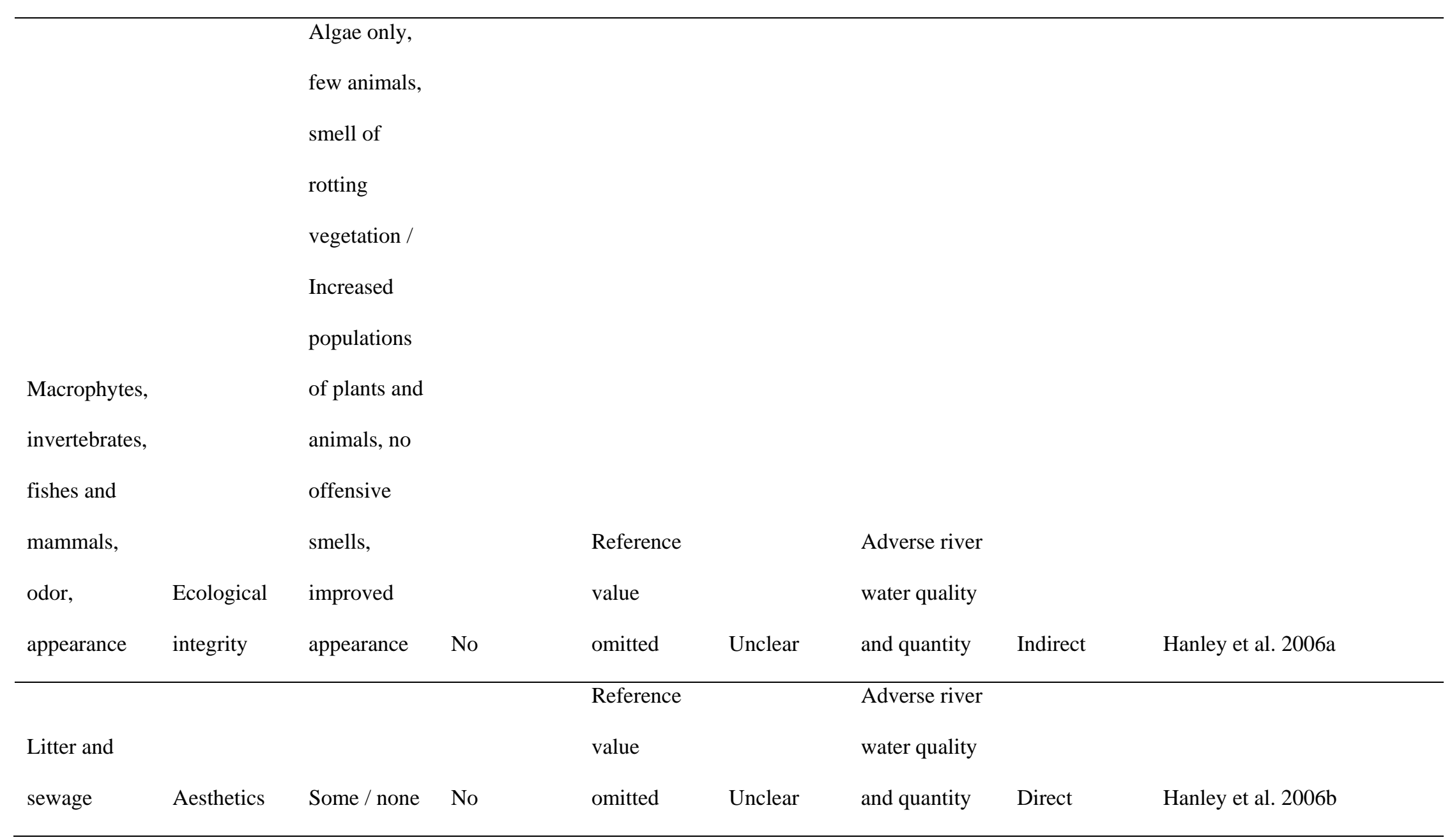


Schultz et al. Restoration Ecology MS Supplementary Document p 4

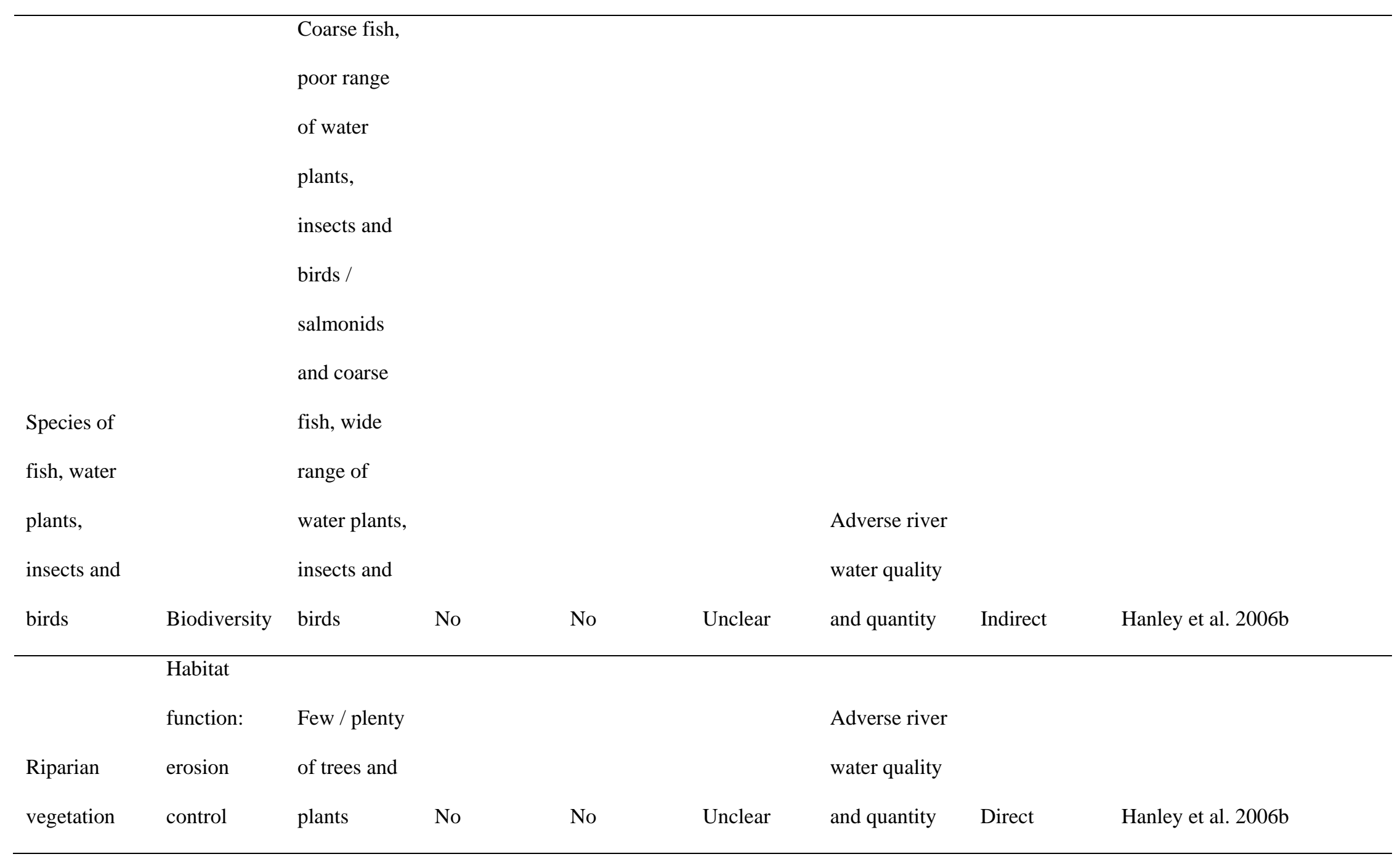


Schultz et al. Restoration Ecology MS Supplementary Document p 5

\begin{tabular}{|c|c|c|c|c|c|c|c|c|}
\hline $\begin{array}{l}\text { Abundance } \\
\text { of wetland }\end{array}$ & & & & & & & & \\
\hline dependent, & & & & & & & & \\
\hline dryland & & Percent & & & & & & \\
\hline dependent & & relative to & & & & & & \\
\hline and bay & & historical & & & & & & \\
\hline dependent & & pre-impaired & & & & Adverse & & \\
\hline species & Productivity & values & Yes & Yes & Yes & hydrology & Indirect & Milon \& Scrogin 2006 \\
\hline & & Percent & & & & & & \\
\hline & & relative to & & & & & & \\
\hline Lake and & & historical & & & & & & \\
\hline wetland & Habitat & pre-impaired & & & & Adverse & & \\
\hline water values & quantity & values & Yes & Yes & Yes & hydrology & Direct & Milon \& Scrogin 2006 \\
\hline Protected & & & & Reference & & & & \\
\hline bird species & & & & value & & & & \\
\hline number & Biodiversity & $14 / 34$ & Yes & omitted & Unclear & Habitat loss & Indirect & Birol \& Cox 2007 \\
\hline & & & & Reference & & & & \\
\hline & Habitat & & & value & & & & \\
\hline Wetland area & quantity & $100 / 347$ km & Yes & omitted & Unclear & Habitat loss & Direct & Birol \& Cox 2007 \\
\hline
\end{tabular}


Schultz et al. Restoration Ecology MS Supplementary Document p 6

\begin{tabular}{|c|c|c|c|c|c|c|c|c|}
\hline Otter holt & Habitat & & & & & & & \\
\hline construction & quantity & Yes / no & Yes & Yes & Unclear & Habitat loss & Direct & Birol \& Cox 2007 \\
\hline \multicolumn{9}{|l|}{ Suitability } \\
\hline for playing in & & Impossible / & & & & Adverse water & & \\
\hline \multirow[t]{4}{*}{ the river } & Recreation & possible & No & No & Unclear & quality & Direct & Nakatani et al. 2007 \\
\hline & & None / carp, & & & & & & \\
\hline & & crucians, & & & & & & \\
\hline & & loaches, & & & & & & \\
\hline Fish species & & bitterlings, & & & & Adverse water & & \\
\hline \multirow[t]{4}{*}{ number } & Biodiversity & killifish & Yes & Yes & Unclear & quality & Indirect & Nakatani et al. 2007 \\
\hline & Habitat & & & & & & & \\
\hline & function: & & & & & & & \\
\hline & erosion and & & & & & Adverse & & \\
\hline Channel & flood & Straightened & & & & hydrology and & & \\
\hline form & control & / natural & No & Yes & Unclear & water quality & Direct & Kerr \& Sharp 2008 \\
\hline
\end{tabular}


Schultz et al. Restoration Ecology MS Supplementary Document p 7

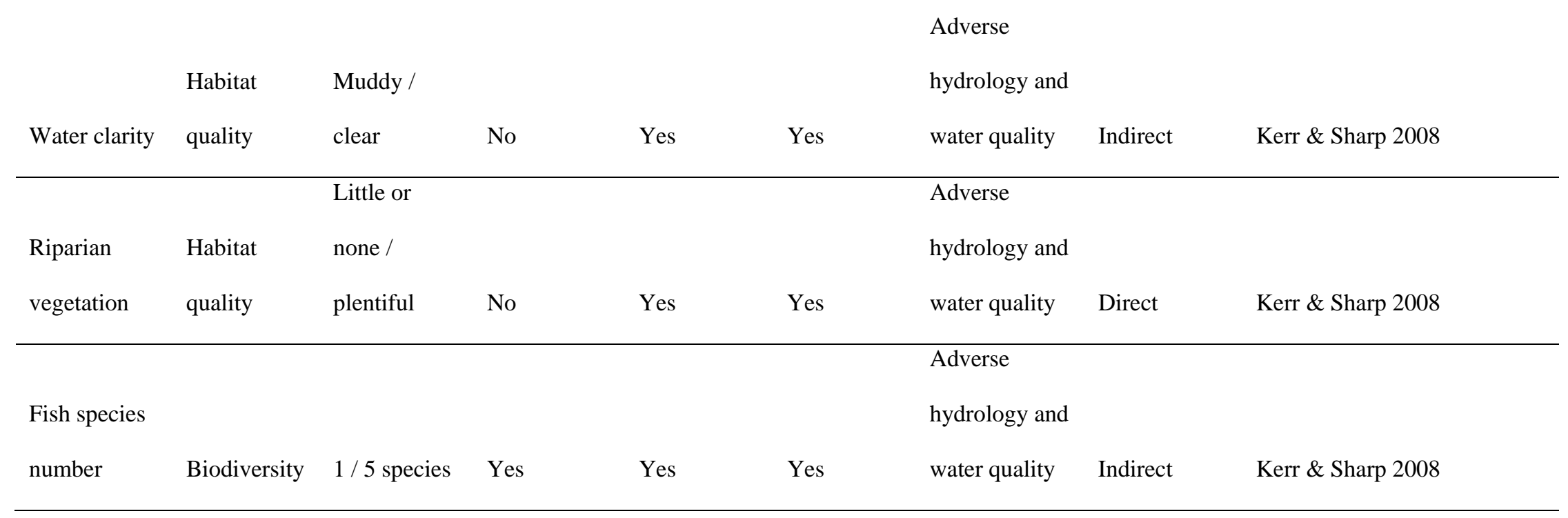




\begin{tabular}{|c|c|c|c|c|c|c|c|c|}
\hline & Habitat & & & & & $\begin{array}{l}\text { Adverse } \\
\text { hydrology and }\end{array}$ & & \\
\hline Fish habitat & quantity & $1 / 4 \mathrm{~km}$ & Yes & Yes & Yes & water quality & Direct & Kerr \& Sharp 2008 \\
\hline Fish & & $146 / 1612$ & & & & Climate & & \\
\hline abundance & Productivity & trout & Yes & Yes & Yes & change & Indirect & Tseng \& Chen 2008 \\
\hline
\end{tabular}




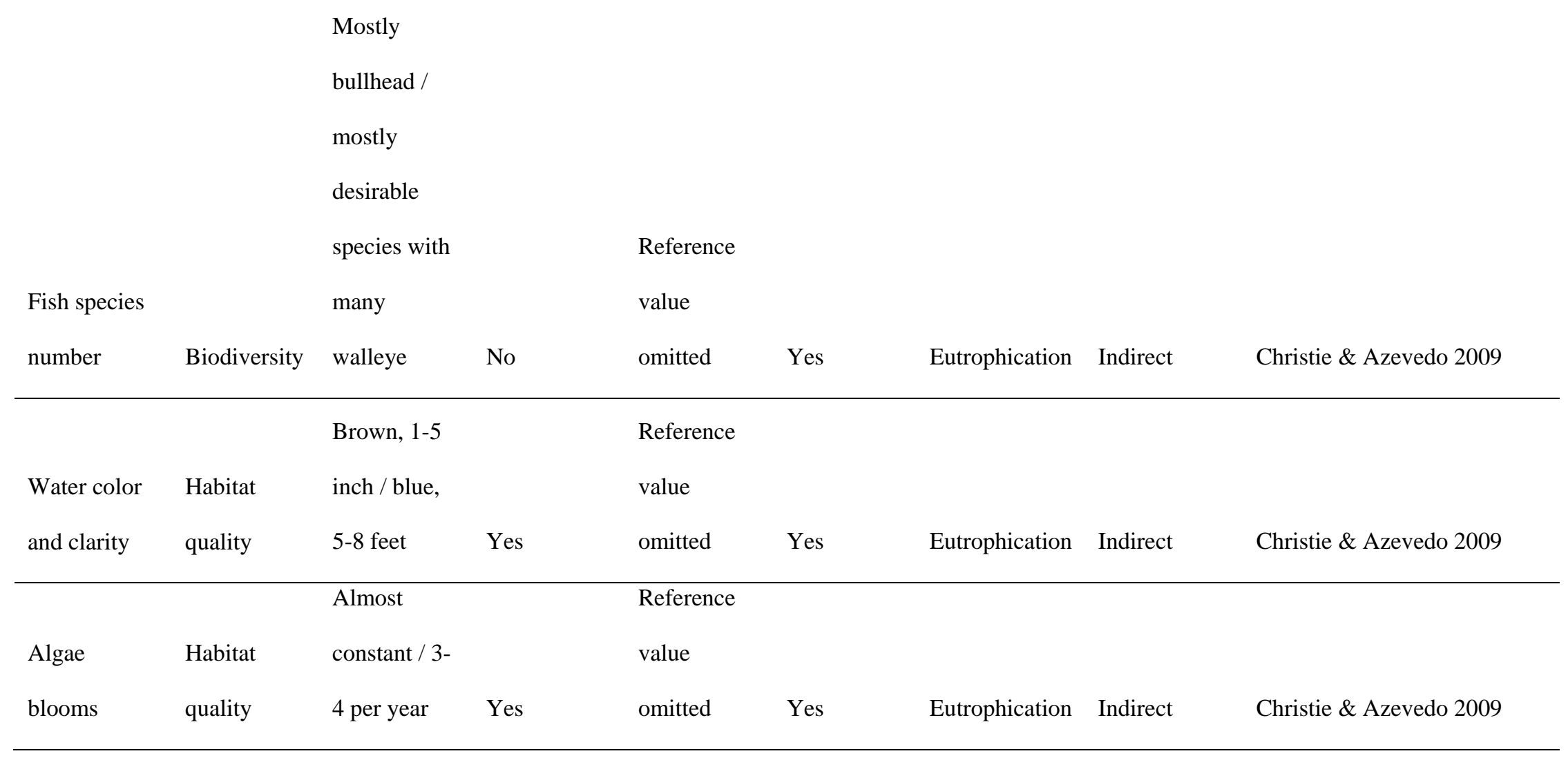


Schultz et al. Restoration Ecology MS Supplementary Document p 10

Reference

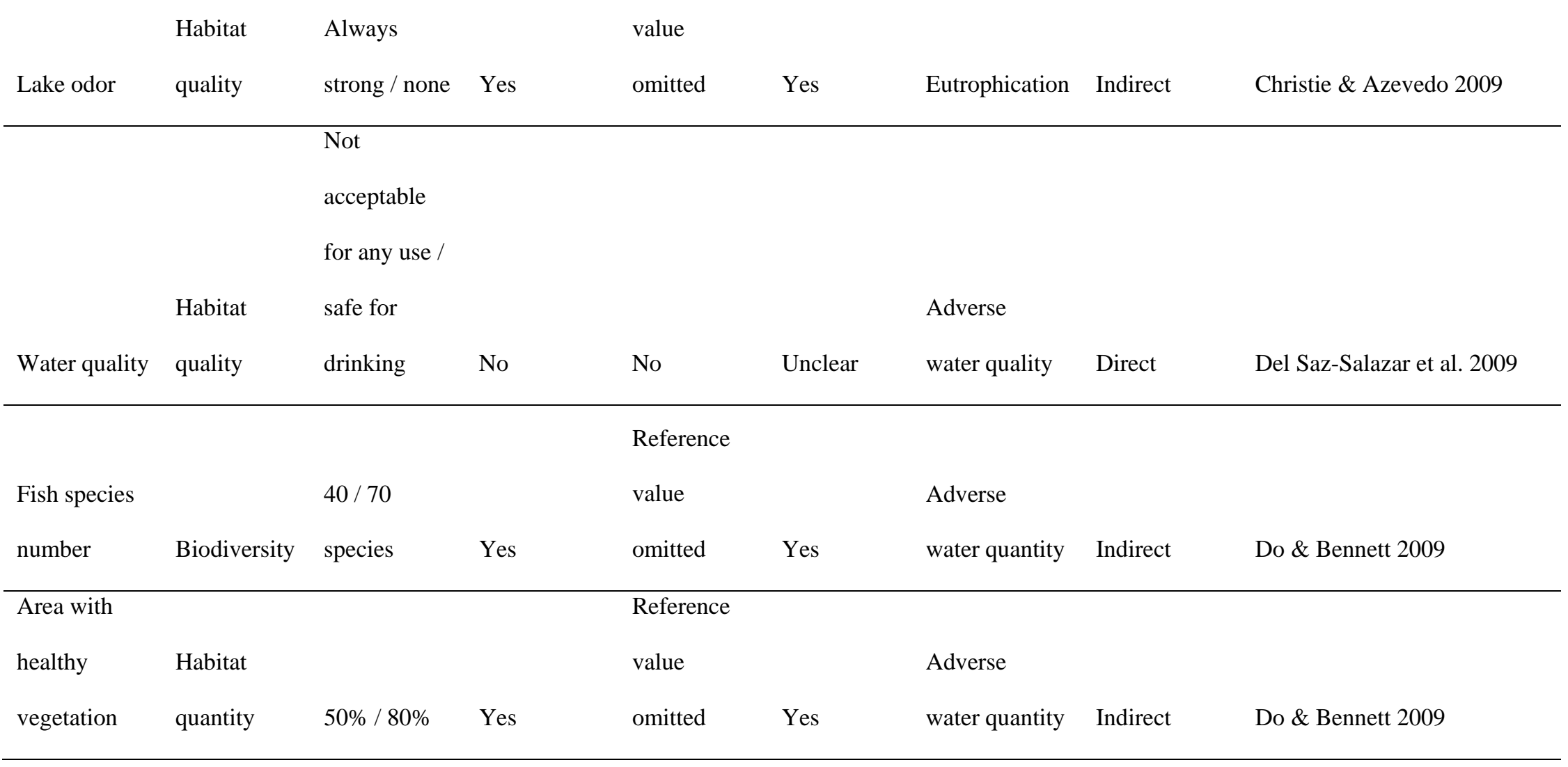


Schultz et al. Restoration Ecology MS Supplementary Document p 11

\begin{tabular}{|c|c|c|c|c|c|c|c|c|}
\hline \multirow[b]{2}{*}{ Number of } & \multirow[b]{3}{*}{ Productivity } & \multirow{2}{*}{\multicolumn{2}{|c|}{$150 / 450$}} & \multicolumn{4}{|c|}{ Reference } & \multirow[b]{3}{*}{ Do \& Bennett 2009} \\
\hline & & & & value & & Adverse & & \\
\hline Sarus cranes & & birds & Yes & omitted & Yes & water quantity & Indirect & \\
\hline & Habitat & Wooded / & & & & & & Fenichel et al. 2009; Hoehn et \\
\hline Wetland type & quality & marsh & Yes & Yes & Yes & Habitat loss & Direct & al. 2010 \\
\hline \multicolumn{9}{|l|}{ Habitat for a } \\
\hline \multicolumn{9}{|l|}{ taxon or } \\
\hline guild (e.g., & & Poor (few & & & & & & \\
\hline songbirds, & & species) / & & & & & & \\
\hline wild & Habitat & excellent & & & & & & \\
\hline flowers): five & quality / & (variety of & & & & & & Fenichel et al. 2009; Hoehn et \\
\hline \multirow[t]{2}{*}{ bioindicators } & productivity & species) & Yes & Yes & Yes & Habitat loss & Indirect & al. 2010 \\
\hline & Habitat & & & & & & & Fenichel et al. 2009; Hoehn et \\
\hline Wetland area & quantity & $5 / 16$ acres & Yes & Yes & Yes & Habitat loss & Direct & al. 2010 \\
\hline \multicolumn{9}{|l|}{ Number of } \\
\hline salmon & & & & Referenc & & & & \\
\hline passing fish & & $3000 / 9000$ & & value & & Habitat loss or & & \\
\hline ladder & Productivity & fish & Yes & omitted & Yes & fragmentation & Direct & Håkansson 2009 \\
\hline
\end{tabular}


Schultz et al. Restoration Ecology MS Supplementary Document p 12

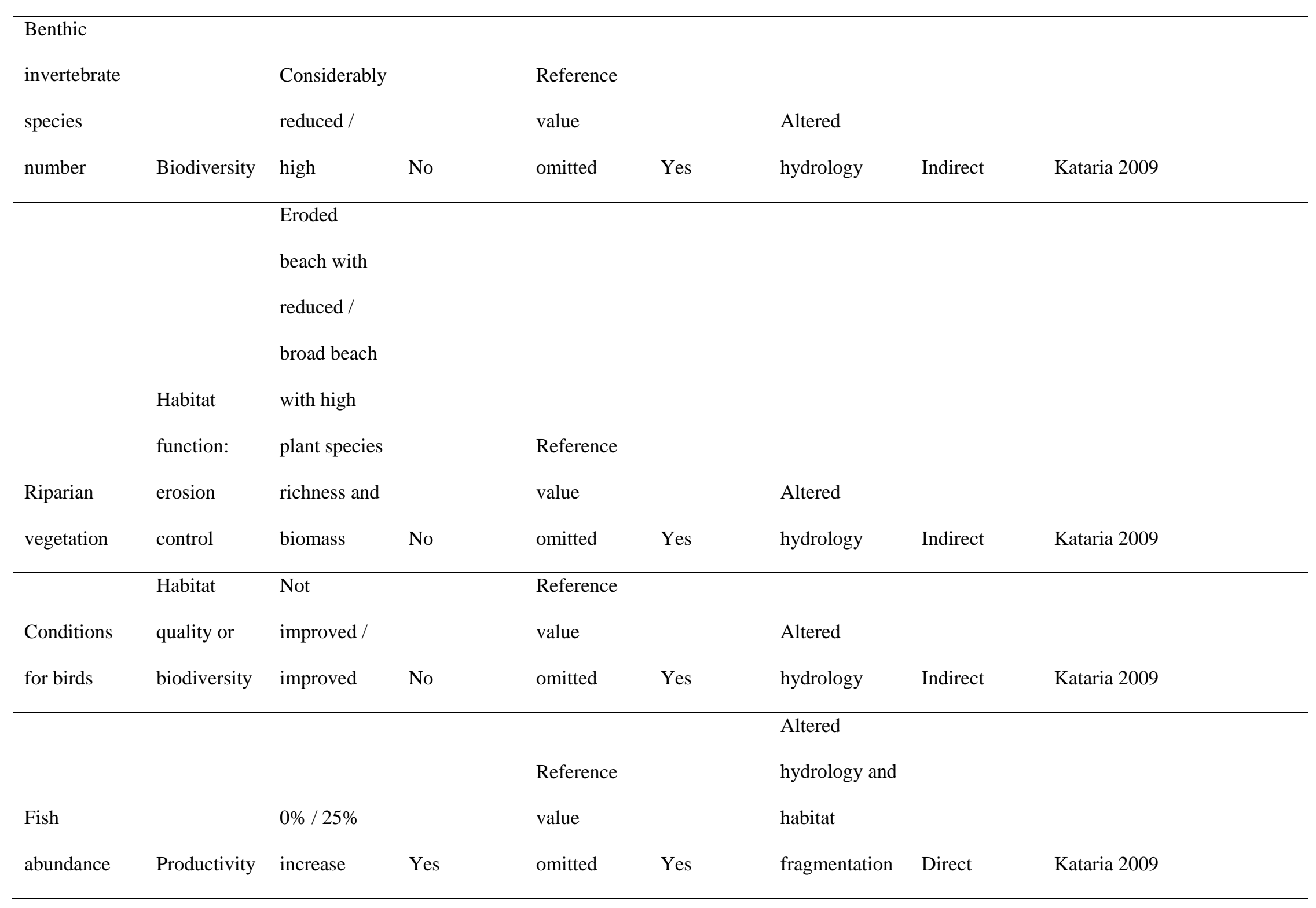


Schultz et al. Restoration Ecology MS Supplementary Document p 13

\begin{tabular}{|c|c|c|c|c|c|c|c|c|}
\hline & & Reduced / & & & & Invasive & & \\
\hline Water clarity & Aesthetics & improved & No & No & Yes & species & Direct & McIntosh et al. 2010 \\
\hline \multicolumn{9}{|l|}{ Native } \\
\hline animals and & & Reduced / & & & & Invasive & & \\
\hline plants & Biodiversity & not reduced & No & No & Yes & species & Indirect & McIntosh et al. 2010 \\
\hline \multicolumn{9}{|l|}{ Risk of } \\
\hline injury or & Human & Higher / not & & & & Invasive & & \\
\hline illness & health & higher & No & No & Yes & species & Direct & McIntosh et al. 2010 \\
\hline \multicolumn{9}{|l|}{ Sport fishing } \\
\hline \multicolumn{9}{|l|}{ and } \\
\hline swimming & & Reduced / & & & & Invasive & Direct, & \\
\hline \multirow[t]{2}{*}{ opportunities } & Recreation & not reduced & No & No & Yes & species & Indirect & McIntosh et al. 2010 \\
\hline & & & & & & Habitat lo & & \\
\hline Condition of & Habitat & & & & & and water & & \\
\hline waterholes & quality & Poor / good & No & Yes & Yes & quality & Indirect & Zander \& Straton 2010 \\
\hline
\end{tabular}


Schultz et al. Restoration Ecology MS Supplementary Document p 14

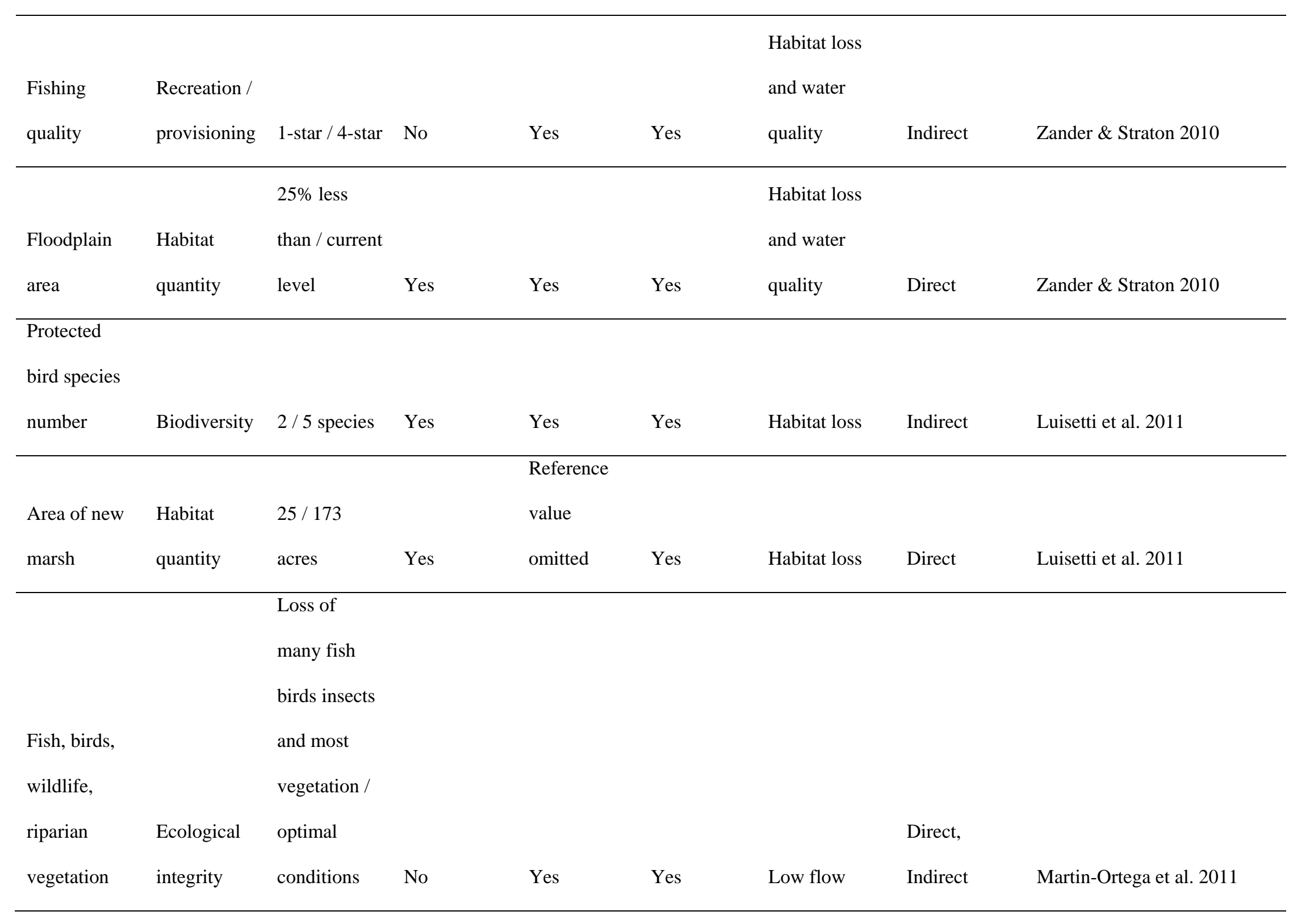


Schultz et al. Restoration Ecology MS Supplementary Document p 15

\begin{tabular}{|c|c|c|c|c|c|c|c|c|}
\hline & Habitat & & & & & & & \\
\hline & function: & $740,000 /$ & & & & & & \\
\hline & carbon & 800,000 car & & & & & & \\
\hline Carbon & capture and & emissions & & & & & & \\
\hline \multirow[t]{4}{*}{ capture } & storage & stored & Yes & Yes & Yes & Habitat loss & Indirect & Pattison et al. 2011 \\
\hline & Habitat & 6 million / & & & & & & \\
\hline & function: & 6.8 million & & & & & & \\
\hline & erosion & tons not & & & & & & \\
\hline \multirow[t]{4}{*}{ Erosion } & control & eroded & Yes & Yes & Yes & Habitat loss & Indirect & Pattison et al. 2011 \\
\hline & Habitat & 1.1 billion / & & & & & & \\
\hline & function: & 1.2 billion & & & & & & \\
\hline & flood & cubic meters & & & & & & \\
\hline \multirow[t]{4}{*}{ Flood control } & control & of water & Yes & Yes & Yes & Habitat loss & Indirect & Pattison et al. 2011 \\
\hline & Habitat & & & & & & & \\
\hline & function: & 4500 / 5000 & & & & & & \\
\hline & water & truck loads & & & & & & \\
\hline \multirow[t]{3}{*}{ Water quality } & purification & of fertilizer & Yes & Yes & Yes & Habitat loss & Indirect & Pattison et al. 2011 \\
\hline & & Percent & & & & & & \\
\hline & Habitat & relative to & & & & & & \\
\hline Wetland area & quantity & 1968 values & Yes & Yes & Yes & Habitat loss & Direct & Pattison et al. 2011 \\
\hline
\end{tabular}


Schultz et al. Restoration Ecology MS Supplementary Document p 16

\begin{tabular}{|c|c|c|c|c|c|c|c|c|}
\hline & & \multicolumn{7}{|c|}{1.8 million / } \\
\hline & & \multicolumn{7}{|c|}{2 million } \\
\hline Breeding & Habitat & \multicolumn{7}{|c|}{ breeding } \\
\hline ducks & quantity & pairs & Yes & Yes & Yes & Habitat loss & Indirect & Pattison et al. 2011 \\
\hline
\end{tabular}

